\title{
Optimal Pricing under The Consumer Segmentation in Dual Channel Supply Chain
}

\author{
Xiaoyu Zhu ${ }^{1, a^{*}}$, Yanyi Xu ${ }^{2}$, Tijun Fan ${ }^{3}$ \\ ${ }^{1,2,3}$ East China University of Science and Technology \\ Business School, Shanghai, P.R.China \\ azxy910613@hotmail.com
}

Key words: Consumer Segmentation; Online Intermediary; Dual Channel; Optimal Pricing Abstract.Based on the fast development of E-commerce and heterogeneity of consumer behavior, in this paper, we develop a hierarchical selection model characterizing consumers' acceptance of online channel, and then study the optimal pricing strategy of suppliers in a dual channel supply chain. We conclude that the supplier should actively communicate with the online intermediaries for cooperation to improve customers' online shopping experience. For the online intermediaries, they should not only focus on improving consumer acceptance of online channels, but should strive to improve their product diversity, which will increase the proportion of type-primary consumers.

\section{Introduction}

The optimal pricing in dual channel supply chain catches the scholars' eyes in the academic circles both in homeland and abroad. Most literature at present use the method of game optimization decision-making and set the objective function as maximizing the profit either in supply chain parties or the whole supply chain. Arya ${ }^{1}$ has proposed that supplier encroachment can directly control the retail channel's sales prices in the case of information symmetry, which led her to gain more profit through the lower wholesale prices. Li Zhuoxin ${ }^{2}$ discussed the retailers to obtain more information than the supplier in double channel pricing problem on the basis of the study of Arya. She concluded that under the information asymmetric, the retailers can prophet intensified dual marginal utility with its information advantage to make supplier encroachment damage themselves, which is all that matters. Therefore, Suppliers prefer to selling the goods to the retailer who has no information advantage or retailers willing to information sharing.Through the literature review shows above, about the pricing strategy in dual channel, most researches divided the channel into retail and direct online channel. This paper will put the intermediary into our models as a participant. Because of their advantage of its own win the trust of consumers. On the aspect of pricing, most papers mainly focus on the customers' purchase cost, channel preference and sale price factors. However, in this paper, we build the different sources of demand function on the basis of using the layered consumer choice model.

\section{Problem description and assumptions}

Hypothesis there is a monopoly enterprise in the market selling goods to consumers through two channels. One is the traditional retail channel which is the brand franchise stores such as apple and ZARA, the other is a mobile internet platform (such as Tmall, VIP) that we call them as intermediary. In order to discuss convenient, we suppose the goods in the franchise store has no quality problems while in the intermediary, the goods may be gray and have quality issues. Based on the consumer hierarchical selection model in reference 4, we subdivide the consumer groups into two types. The first kind is brand-primary, the consumers in which often consider the brand at first when buying goods, so their purchase behavior is directly to the brand monopolized shop. The second is type-primary that the consumers decide the type of goods at first before buying. They like fashion way with the continuous development of mobile Internet. In addition to considering price factors, most of them consider the purchasing cost, consumption experience, as well as a variety of value-added services in the process of consumption. So their purchasing behavior is going to choose 
the intermediary to buy goods they need.

\section{Basic Model}

In this paper, the consumers we discussed are heterogeneous and their willingness to pay for homogeneous commodities is $v$, obeying the uniform distribution between 0 and 1 . In retail channel, consumer can observe the product directly. The bigger of $\phi$ suggests that the higher acceptance for buying goods in the online channel.

After the analysis above, for the brand-primary consumers, although they would only consider one brand of commodity, they will make the purchase decision after compare the two channels. Suppose the net utility of the brand-primary consumers in retail channels and from the intermediary respectively is $U_{r}^{B}=v-p_{r}, U_{m}^{B}=\phi v-p_{m}$. We can conclude that when $p_{r}-(1-\phi) \leq p_{m} \leq \phi p_{r}$, the demand in retail channel of the brand-primary consumers is $q_{r}^{B}=\alpha\left(1-\frac{p_{r}-p_{m}}{1-\phi}\right)$ and the demand in the intermediary is $q_{m}^{B}=\alpha\left(\frac{p_{r}-p_{m}}{1-\phi}-\frac{p_{m}}{\phi}\right)$.For the type-primary customers, they will compare different brands from various aspects through the intermediary before making purchase decisions. They won't buy goods from the store of one certain brand, so its utility function is $U_{m}^{T}=\phi v-p_{m}$ and then the demand in the intermediary of the type-primary consumers is $q_{m}^{T}=(1-\alpha)\left(1-\frac{p_{m}}{\phi}\right)$.

It is a kind of strategic behavior that suppliers outsource their online channels of operation to the intermediary who has her efficient e-commerce platform that can reduce the operating costs for producers and eventually achieve a win-win effect between both sides. When the suppliers sale goods through the intermediary in online channel, Supplier's income includes wholesale profits of the retail channels and the profit share from intermediary. The profit of the intermediary comes from the online sales and the profit of the retailers comes from the retail channels.

In this time, the target profit function of the three participants is respectively as bellow,

$$
\begin{aligned}
& \prod_{R}\left(p_{r}\right)=\alpha\left(p_{r}-c_{r}-w\right)\left(1-\frac{p_{r}-p_{m}}{1-\phi}\right) \\
& \prod_{M}\left(p_{m}\right)=\left(p_{m}-c_{m}-s\right)(1-\alpha)\left(1-\frac{p_{m}}{\phi}\right)+\alpha\left(p_{m}-c_{m}-s\right)\left(\frac{p_{r}-p_{m}}{1-\phi}-\frac{p_{m}}{\phi}\right) \\
& \prod_{A}\left(p_{r}, w\right)=s(1-\alpha)\left(1-\frac{p_{m}}{\phi}\right)+\alpha s\left(\frac{p_{r}-p_{m}}{1-\phi}-\frac{p_{m}}{\phi}\right)+\alpha w\left(1-\frac{p_{r}-p_{m}}{1-\phi}\right)
\end{aligned}
$$

\section{Equilibrium analysis}

In order to compare with dual channel supply chain with the intermediary, we consider a single retail channel first. In this case, the target customer groups for supplier is only the brand-primary consumers, therefore the demand function for this direct channel is $q_{r}^{B}=\alpha\left(1-p_{d}\right)$ and at this time, the supplier and retailer's game order is the supplier first set the wholesale price and the retailer develop his retail price $p_{r}$ according to the wholesale price.

PROPOSITION 1: The optimal pricing decision set of supplier and retailer without the intermediary in single channel is $\left(w^{1 *}, p_{r}^{1 *}\right)$ where $p_{r}^{1 *}=\frac{3+c_{r}}{4}, w^{1 *}=\frac{1-c_{r}}{2}$. At this point, the maximize income of the supplier and retailer are $\prod_{A}^{1 *}=\frac{\alpha\left(1-c_{r}\right)^{2}}{8} \prod_{R}^{1 *}=\frac{\alpha\left(1-c_{r}\right)^{2}}{16}$.

When suppliers sale goods through the intermediary of online channel, Supplier's income includes wholesale profits share of the intermediary and the revenue from retail channel, while the 
profit of the intermediary comes from the sales revenue of online channel. The game order for the three participants is as follows. First, the Supplier published wholesale price and the sale price in the direct channel, then the retailer develop his retail price. At last, the intermediary develop the online price according to the sales price in retail channel and the wholesale price.

PROPOSITION 2: In the presence of a intermediary in dual channel supply chain, the optimal pricing decision set of suppliers and the intermediary is $\left(w^{*}, p_{d}^{*}, p_{m}^{*}\right)$. Among them,

$$
\begin{aligned}
& w^{*}=\frac{(1-\phi+\alpha \phi)\left(c_{m}-2 s-\phi\right)}{2(2-2 \phi+\alpha \phi)}+\frac{1-c_{r}}{2} \\
& p_{r}^{*}=\frac{\left(x_{1}+\alpha x_{2}\right)\left(c_{m}+s\right)}{2\left(2 x_{1}+\alpha x_{2}\right)}-\frac{1+\alpha+2 \alpha \phi x_{2}}{2\left(2 x_{1}+\alpha x_{2}\right)}+\frac{(1-\phi+\alpha \phi)\left(c_{m}-2 s-\phi\right)}{4(2-2 \phi+\alpha \phi)}+\frac{c_{r}+3}{4} \\
& p_{m}^{*}=\frac{\phi\left(x_{1}+\alpha x_{2}\right)\left(c_{m}+s\right)}{2\left(2 x_{1}+\alpha x_{2}\right)}+\frac{\phi(1-\phi+\alpha \phi)\left(c_{m}-2 s-\phi\right)}{4(2-2 \phi+\alpha \phi)}-\frac{\phi\left(1+\alpha+2 \alpha \phi x_{2}\right)}{2\left(2 x_{1}+\alpha x_{2}\right)}+\frac{\left(c_{r}+3\right)}{4}+\frac{c_{m}+s+1}{2}-\frac{\alpha}{2(1-\phi+\alpha \phi)}
\end{aligned}
$$

\section{Data simulation and analysis}

In this section, we use the Matlab software to do some numerical experiments through several groups of data, in order to examine the supplier's optimal pricing decisions under two different channels. Let the operating costs of direct sales channels and online sales respectively be $c_{r}=0.1 c_{m}=0.01$. Suppliers will gain the rebate for each product from the intermediary $s=0.2$.

\section{A. The influence of $\phi$ on the pricing strategy}

Let $\phi$ changes between 0.1 and 1 and $\alpha=0.30 .7$. Then the retail price, wholesale price, the online price and the benefits of suppliers when the supplier choose dual channel supply chain are respectively shown in figure 1 and figure 2 as below.

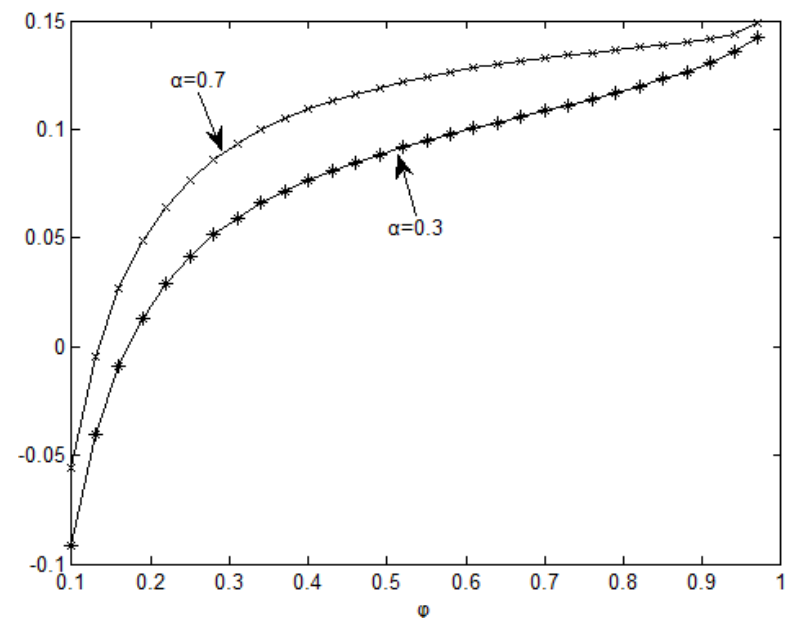

Fig. 1. The profit of the supplier

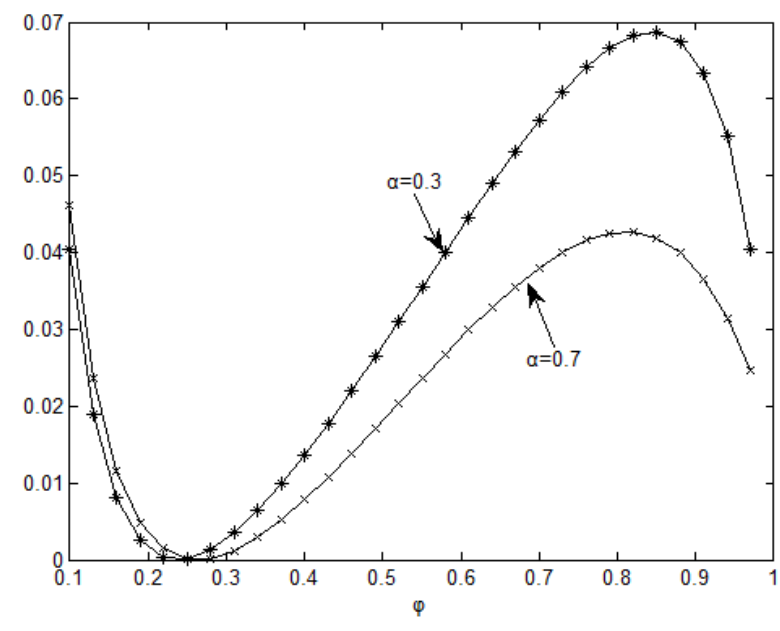

Fig. 2. The profit of the intermediary

From figure 1, we can see the supplier's revenue will be increased obviously at first and then became slowly with the increase of consumer acceptance for network channels increased. While from figure 2, the benefits of the intermediary drop at first, then arise and at last drop again significantly with the increase of consumer acceptance for network channels increased.

Nowadays, with the mobile Internet technology and related logistics technology becoming mature, consumer acceptance of online channel will gradually increase. In such case, supplier shall actively cooperate with intermediaries to gain more profit through optimizing the structure of dual channel supply chain. At the same time, Intermediaries should constantly improve the consumer shopping experience actively and cooperate with supplier by means of information sharing cooperation to make sales strategy actively with suppliers in order to achieve win-win situation.

\section{B. The influence of $\alpha$ on the pricing strategy}

Let $\alpha$ changes between 0.1 and 1 and $\phi=0.40 .8$. Then the retail price, wholesale price, the 
online price and the benefits of suppliers when the supplier choose dual channel supply chain are respectively shown in figure 3 and figure 4 as below.

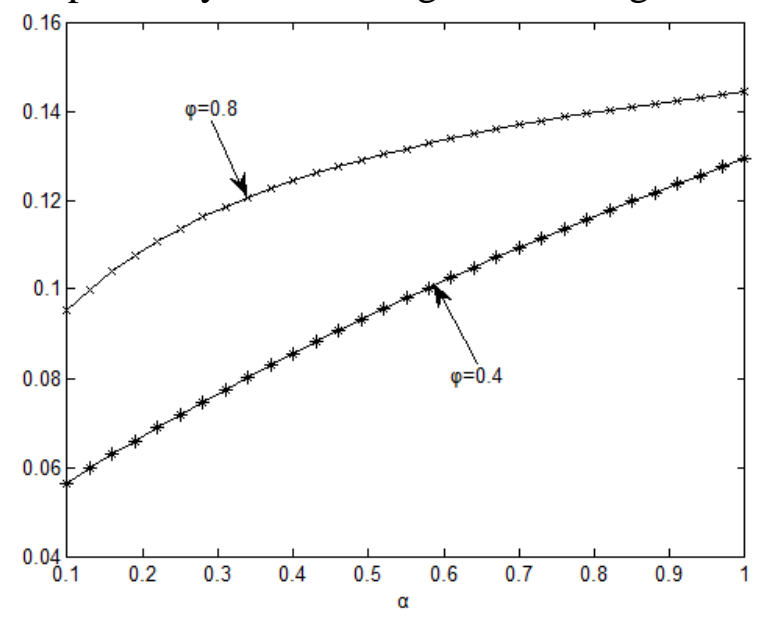

Figure. 3. The profit of the supplier

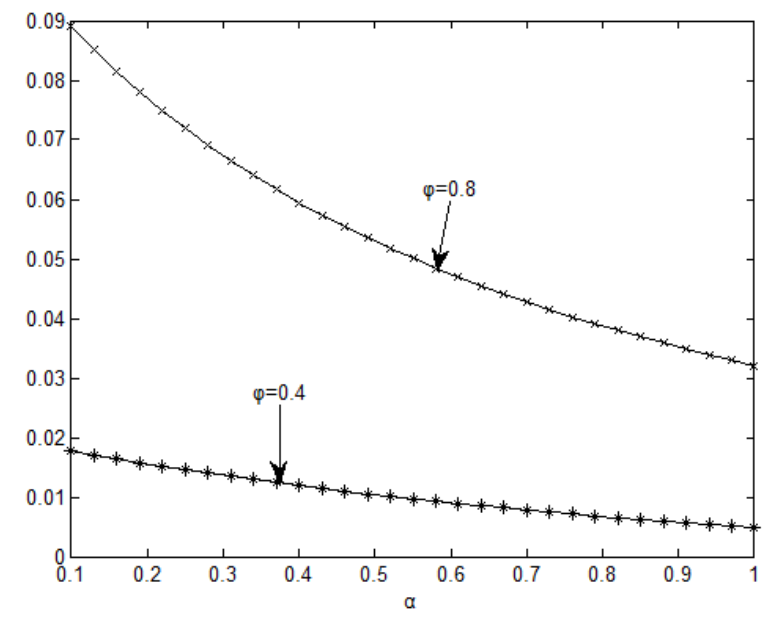

Figure. 4.The profit of the intermediary

From figure 3, we can see the supplier's revenue will be increased slightly the increase of brand oriented consumer ratio increased. While from figure 4, the benefits of the intermediary drop slowly with the increase of brand oriented consumer ratio increased.

When consumer acceptance of Internet channel is low, the impact of $\alpha$ on the supplier's earnings is more obvious than the intermediary. When $\phi$ is high, the influence of $\alpha$ on intermediary is more obvious effect than suppliers. Therefore, supplier shall actively cooperate with intermediaries to obtain effective cooperation agreement under information sharing and control the proportion of brand-primary consumers reasonable to reach the optimal benefits both of the suppliers and the intermediary.

\section{Conclusion and prospect}

In this paper, we established a decentralized decision-making model after considering the influence of proportion of brand-primary consumers and type-primary consumers and the degree of consumers' recognition of network channels on suppliers' pricing strategy in dual channel. We conclude that the wholesale and sale price of the goods will be decreased with the increase of consumer acceptance for networking channels and the proportion of brand oriented consumers. Meanwhile, the profit of the supplier will increased obviously. With the diversification of product selection, the mode of outsourcing network marketing channel to intermediary can make supplier itself and intermediary realize win-win outcome, so as to obtain more profits. Besides, the supplier should communicate with intermediary cooperation actively on the basis of perfecting its own brand to improve the network shopping experience. For intermediaries, they don't need to blindly demand to improve consumer acceptance of online channels, but should strive to improve their own platform products richness, to increase the proportion of type oriented consumers.

In the end, we do not take the commodity competition in intermediary's platform into account in order to highlight the income difference between dual channels and single channel. At the same time, we also did not consider whether the entity experience in direct channel affects consumer buying behavior. Thus, the pricing decisions under the competition in the intermediary in dual channel will be our next research direction.

\section{Reference}

[1]Arya A, Mittendorf B, Sappington DEM. The Bright Side of Supplier Encroachment[J]. Marketing Science. 2007, Vol.26(NO.5): 651-659.

[2]Li Z, Gilbert SM, Lai G. Supplier Encroachment under Asymmetric Information[J]. Management Science. 2014, Vol.60(No.2): 449-462. 
International Conference on Engineering Management, Engineering Education and Information Technology (EMEEIT 2015)

[3]Chiang WK, Chhajed D,Hess JD.Direct marketing indirect profits:A strategic analysis of dual-channel supply chain design.Management Science, 2003, 49(1): 1-20.

[4]Kök A G, Xu Y. Optimal and Competitive Assortments with Endogenous Pricing Under Hierarchical Consumer Choice Models[Z]. 2011: 57, 1546-1563. 